\section{Book of numbers}

Vaclav Smil

How Many People Can the Earth Support? By Joel E. Cohen. Norton: 1995. Pp. 532. $\$ 30, £ 22.50$. UK publication date, 27 March.
THE reader will never get the definitive answer to the question posed by the title of this book. That is, of course, the way it should be. As the author knows well, any attempt to offer and justify such a number is misplaced; the question has no single answer today and it will not have one tomorrow - at least, none from unprejudiced enquiry. Naturally, the catastrophists who long ago decided that the world already has too many people and the techno-fixers who are itching to terraform Mars all have their own the first case, an irrelevant astronomical total in the second.

Those of us who prefer reality to dogma know that all sorts of natural, technical and social factors constrain human choices about the planet's carrying capacity, but that our understanding of these limits constantly evolves and changes, and that their acuteness and permanence are vigorously debated, disdenied. If one insists on numbers, then the only sensible way out is to give conditional estimates: that is, given such and such a combination of future choices, available resources, techniques and social arrangements, then it is most likely that the Earth could support so many people. Usually it is only a short time become either completely indefensible or highly questionable, and one may then begin a new round of scenariobuilding. These are futile exercises, but the question is here to stay.

One way for a writer to dispose of the question would be to flip it aside by pointing out some of these key realities in a snappy essay. But Joel Cohen chooses instead to smother it. The essay is still there - but the reader must first wade through some 260 pages to reach it. The main reason for the postponed appearance is clear. The author, head of the Labora-tory of Populations at Rockefeller University, New York, has done a great deal of interdisciplinary work, but in this book, which offers a perfect opportunity for including the widest range of disciplines and perspectives, he is very much a demographer.

Before attempting to answer the unanswerable, he devotes a lot of space (too much, I think) to a systematic description of past population growth and its longanswers: no more than about a billion in puted and, in some instances, even before the many requisite assumptions term projections. He takes the first topic, which consumes a quarter of the text, from uncertain estimates of total human numbers at the time of the emergence of agriculture to an extended discussion of various growth curves. Forecast reviews, occupying the next quarter of the book, look first at various projection methods and scenarios and then in extensive detail - with summaries of original publications followed by the author's comments - at eight different estimates of human carrying capacity published, by individuals or teams, between 1891 and 1991 .

Only then does Cohen start moving beyond the demographic confines by looking at the concept of carrying capacity in ecological terms and by assessing its worth for humans. Again, this is done in a very deliberate way, including an appendix of two dozen verbal definitions of human carrying capacity printed in small type.

None of this is unimportant, most of it is relevant and much of it is interesting. But who is it aimed at? Norton books are intended to reach a wide readership, but the material here may simply be too much for a lay reader and is mostly too well known to be of value to any serious student of human population. I believe the dilatory stratagem works against the book. Entering in medias res, after just a crisp brief recount of the past - which, in this case, is no guide for the future would have been much better.

Two-thirds into the book, we come to its real core, to what it is all about: human choices. To me the single most important part of the book is a list of 11 simple questions, beginning with "How many at what average level of material well-being?" and "How many with what distribution of material well-being?" and ending with "How many for how long?" and "How many with what values, tastes and fashion?". Reflecting on these questions and trying to answer them in both a personal and a detached way would make any serious reader richly aware of the almost exhilarating indeterminacy of the outcome - and of the immense individual and collective responsibility for the fate of the species.

Unfortunately, Cohen then soldiers on for another hundred pages. Realizing the enormous variety of constraints and opportunities that will shape the human future, he chooses a single case study to illustrate the range of long-term predictions of carrying capacity. He looks at

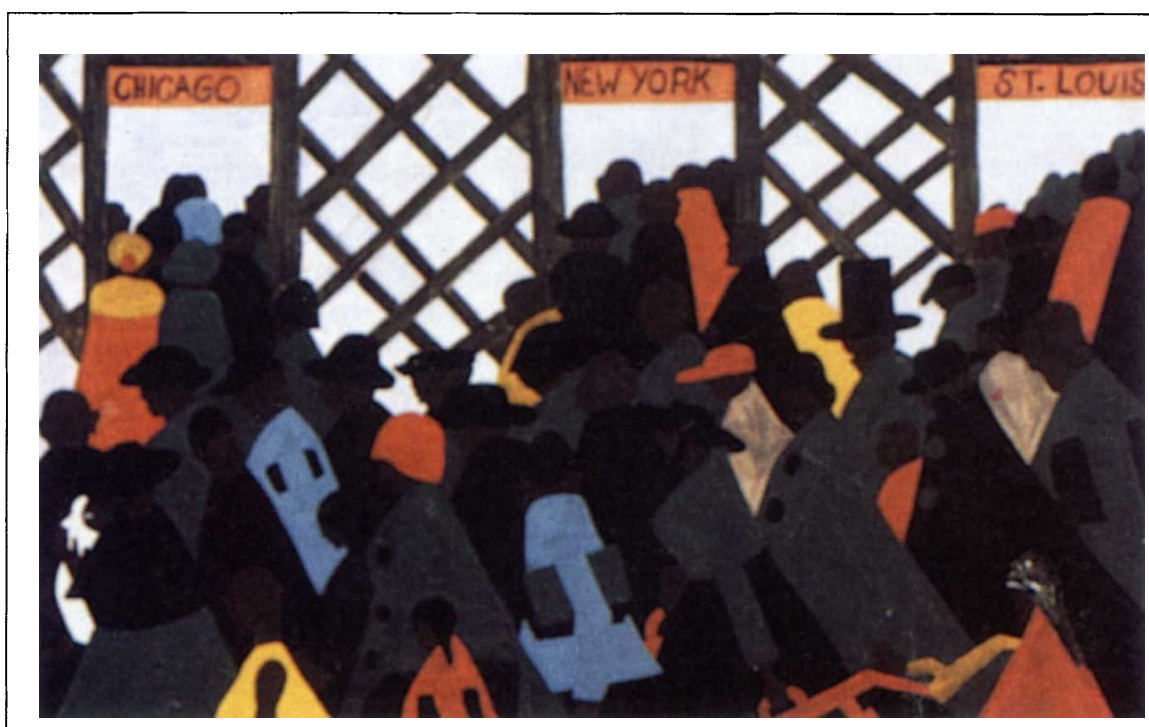

BETWEeN 1917 and 1920, in the largest internal migration in North America's history, some 450,000 African-Americans left the rural south in search of employment and freedom in the north. The move was commemorated in a series of paintings by the American artist Jacob Lawrence entitled The Migration of the Negro. This panel, painted in the 1940s, shows people queuing at a railroad for tickets to the industrial cities of the north. It appears in The Settling of North America: The Atlas of the Great Migrations into North America from the Ice Age to the Present edited by Helen Hornbeck Tanner. The text is written by a team of acclaimed historians and illustrated with 100 full-colour maps as well as with photographs, illustrations and detailed timelines. Macmillan Publishing USA, \$39.95. 